\title{
KINETIC AND THERMODYNAMIC BEHAVIORS OF SOIL UREASE AS AFFECTED BY UREASE INHIBITORS
}

\author{
Y.H. Juan ${ }^{1,2}$, Z.H. Chen ${ }^{1}$, L.J. Chen ${ }^{1 *}$, Z.J. Wu ${ }^{1}$, R. Wang ${ }^{2}$, W.T. Sun ${ }^{2}$ and \\ Y.L. Zhang ${ }^{1}$ \\ ${ }^{1}$ Institute of Applied Ecology, Chinese Academy of Sciences, P. O. Box 417, Shenyang 110016, \\ People's Republic of China; ${ }^{2}$ Liaoning Academy of Agricultural Sciences, Shenyang 110161, \\ People's Republic of China. *Corresponding author: ljchenchina@hotmail.com
}

\begin{abstract}
The kinetic characteristics of soil urease have attracted great attention, but little information was available on its kinetic and thermodynamic behaviors as affected by urease inhibitors and temperature. With black soil (Pachic Udic Mollisol) in Heilongjiang Province of Northeast China as a test soil, an incubation test was conducted to investigate the effect of urease inhibitors (hydroquinone, HQ; phenyl phosphorodiamidate, PPD; N-(n-Butyl) thiophosphoric triamide, NBPT) on kinetic and thermodynamic behaviors of soil urease at $10^{\circ} \mathrm{C}, 20^{\circ} \mathrm{C}$ and $30^{\circ} \mathrm{C}$. The results showed that all tested inhibitors increased $\mathrm{K}_{m}$ and decreased $\mathrm{V}_{\max }$, behaving as mixed inhibitors to soil urease. With increasing temperature, the $\mathrm{K}_{m}$ and $\mathrm{V}_{\max }$ values increased significantly. With incubation time, $\mathrm{K}_{m}$ decreased, while $\mathrm{V}_{\max }$ significantly increased. Compared with control, treatment HQ decreased soil urease thermodynamic parameters $\mathrm{Ea}, \Delta \mathrm{H}$, and $\mathrm{Q}_{10}$, but in PPD and NBPT treatments, the parameters increased slightly. The $\mathrm{Q}_{10}$ and $\Delta \mathrm{H}$ of soil urease decreased slightly with increasing temperature. Among test inhibitors, PPD and NBPT were more effective in influencing the kinetic and thermodynamic behaviors of urease in black soil. The variations in kinetic and thermodynamic parameters indicated that the effects of urease inhibitors on soil urease are greater on kinetic behaviors rather than on thermodynamic ones.
\end{abstract}

Keywords: kinetic parameters, thermodynamic parameters, soil urease, urease inhibitors, temperatures

\section{INTRODUCTION}

Urea fertilizer is the predominant solid nitrogen (N) fertilizer in Chinese agriculture, and constitutes > $50 \%$ national nitrogenous fertilizer consumption (Zhu and Chen, 2002). However, due to the rapid hydrolysis of its amide $\mathrm{N}$ by reaction with the enzyme urease, significant loss of urea $\mathrm{N}$ through $\mathrm{NH}_{3}$ volatilization and $\mathrm{NO}_{3}^{-}$leaching could occur, and thus, a definite decrease of urea $\mathrm{N}$ use efficiency is observed (Nannipieri et al., 1990; Blennerhassett et al., 2006). One effective approach to mitigating these problems is to use compounds that could inhibit soil urease activity and retard the urea hydrolysis when applied to soils together with urea fertilizer (Bremner and Chai, 1989; Wang 
et al., 1991; Byrnes and Freney, 1995; Varel, 1997; Gioacchini et al., 2002; Singh et al., 2008).

A large number of compounds have been tested as urease inhibitors (Beyrouty et al., 1988; Bremner and Chai, 1989; Cai et al., 1989; Wang et al., 1991; Byrnes and Freney, 1995; Gioacchini et al., 2002). Among the numerous urease inhibitors that have been verified, phosphoroamides (especially phenyl phosphorodiamidate (PPD) and N-(nbutyl) thiophosphoric triamide (NBPT)) have been reported to be very effective at a relatively low dose for inhibiting urease activity (Pedrazzini et al., 1987; Keerthisinghe and Freney, 1994; Luo et al., 1994), retarding urea hydrolysis (Chai and Bremner, 1987) and delaying or decreasing $\mathrm{NH}_{3}$ volatilization (Pedrazzini et al., 1987; Wang et al., 1991). However, due to the lower cost of hydroquinone (HQ) and its effect on soil $\mathrm{N}$ transformation processes, this compound has also attracted more attention (Yeomans and Bremner, 1986; Wang et al., 1991).

To examine the kinetics of soil urease, some studies focused on humus-urease complexes (Nannipieri et al., 1978), extracted urease from soil (Nannipieri et al., 1982) and immobilized urease (Makboul and Ottow, 1979; Lai and Tabatabai, 1992; Gianfreda et al., 1992). Juan et al (2009) have studied the kinetics of soil urease affected by urease inhibitors at contrasting moisture regimes. However, little is known about the kinetic and thermodynamic characteristics of soil urease with amendment of urease inhibitors under different temperature conditions.

The kinetic and thermodynamic behaviors of urease influenced by urease inhibitors would be not only used to unravel the types of inhibition mechanisms of urease inhibitors on urease, but also be used to evaluate the effectiveness of urease inhibitors on urease so as to choose more effective urease inhibitors.

In this paper, an incubation test with important black soil described in Juan et al (2009) was conducted to investigate the behaviour of soil urease as affected by urease inhibitors HQ, PPD and NBPT at $10^{\circ} \mathrm{C}, 20^{\circ} \mathrm{C}$, and $30^{\circ} \mathrm{C}$, with a main objective to provide information about kinetic and thermodynamic characteristics of soil urease and the selection of promising urease inhibitors.

\section{MATERIALS AND METHODS}

\section{Soil and inhibitors}

Surface black soil (Pachic Udic Mollisol, US Soil Taxonomy) $(0-20 \mathrm{~cm})$ from the Hailun Experimental Station of Ecology ( $47^{\circ} 25^{\prime} \mathrm{N}, 126^{\circ} 46^{\prime} \mathrm{E}$, altitude $204 \mathrm{~m}$ ), Chinese Academy of Sciences, in Heilongjiang Province of Northeast China, was sampled after the harvest of maize in a maize-soybean rotation system. Eight soil cores were collected and pooled as composite sample. After removing plant roots and debris, soil samples were sieved $(<2 \mathrm{~mm})$, air-dried in shade, and stored for analysis.

Some physicochemical characteristics of the surface soil determined as described by Lu (2000) are $\mathrm{pH} 6.45$ (soil: water ratio, 1:2.5), organic C $29.20 \mathrm{~g} \mathrm{~kg}^{-1}$, total $\mathrm{N} 2.43 \mathrm{~g} \mathrm{~kg}^{-1}$, total $\mathrm{P} 0.82 \mathrm{~g} \mathrm{~kg}^{-1}$, total $\mathrm{S} 0.63 \mathrm{~g} \mathrm{~kg}^{-1}$, alkali-hydrolyzed $\mathrm{N}$ $130.15 \mathrm{mg} \mathrm{kg}^{-1}$, available $\mathrm{P}$ (Olsen P) $105.24 \mathrm{mg} \mathrm{kg}^{-1}$, available $\mathrm{S}$ (extracted by $\mathrm{Ca}\left(\mathrm{H}_{2} \mathrm{PO}_{4}\right)_{2}$-HOAC) $22.9 \mathrm{mg} \cdot \mathrm{kg}^{-1}$, sand $13.85 \%$, clay $34.61 \%$, and silt $51.45 \%$. The sampled area is characterized as mainland monsoon type climate with a mean annual precipitation of about 525 $\mathrm{mm}$, a mean annual temperature of about $3.6^{\circ} \mathrm{C}$, a mean annual frost-free period of about $133 \mathrm{~d}$, and an altitude of about $55 \mathrm{~m}$. 
Urease inhibitors HQ (99\%), PPD (97\%), and NBPT $(99.5 \%)$ were purchased from Sigma (USA), ACROS (Belgium), and Toronto Research Chemicals Inc (Canada), respectively.

\section{Incubation test}

The air-dried soil samples were remoistened at $15 \%(\mathrm{w} / \mathrm{w})$ soil moisture content (SMC), and pre-incubated at $25^{\circ} \mathrm{C}$ for $21 \mathrm{~d}$ to restore microbial activities (Bandick and Dick, 1999; Zornoza et al., 2006). After pre-incubation, the samples were amended with HQ, PPD, and NBPT at rate of $50 \mathrm{mg} \mathrm{kg}^{-1}$ dry soil, and placed in plastic bags with the same amount (about $500 \mathrm{~g}$ inhibitor-added soil of $20 \%$ $\mathrm{SMC}$ ). Then, soil samples were incubated at $10^{\circ} \mathrm{C}, 20^{\circ} \mathrm{C}$ and $30^{\circ} \mathrm{C}$ for $30 \mathrm{~d}$, respectively. During incubation, water loss (assessed by weight) was compensated daily by adding distilled water. Controls (without any urease inhibitor application) were incubated at the temperature condition previously described. Three replicates were used for each treatment.

\section{Urease activity assay}

At 1d, 10d and 30d during incubation, about $5 \mathrm{~g}$ of incubated soil of $20 \%$ SMC in $150 \mathrm{ml}$ stoppered- Erlenmeyer flasks was thoroughly mixed with $5 \mathrm{ml}$ urea solution with a series of concentrations $(5$, $\left.10,15,25,35,45 \mathrm{mmol} \mathrm{L}^{-1}\right)$, and then incubated at $37 \pm 1^{\circ} \mathrm{C}$ for $5 \mathrm{~h}$. After incubation, the residual urea was extracted by $50 \mathrm{ml} 2 \mathrm{~mol} \mathrm{~L}^{-1} \mathrm{KCl}$-acetic phenyl mercury solution for $1 \mathrm{~h}$ on a constant temperature shaker followed by filtration with quantitative filter paper ( $15 \mathrm{~cm})$ (Tabatabai, 1994), and determined by Continuum Flow Auto Analyzer 3 BRAN+LUEBBE, which involves the reaction of urea with diacetylmonoxime (DAM) in the presence of thiosemicarbazide (TSC), $\mathrm{H}_{3} \mathrm{PO}_{4}$, and $\mathrm{H}_{2} \mathrm{SO}_{4}$ under heating. The intensity of red colour formed as a result of this reaction is measured at $527 \mathrm{~nm}$ wavelength. Soil urease activity was expressed as $\mathrm{mg}$ hydrolyzed urea-N $\cdot \mathrm{kg}^{-1}$ dry soil $\cdot 5 \mathrm{~h}^{-1}$.

\section{Kinetics and thermodynamic parameters measurement}

\section{Michaelis kinetic parameters}

The kinetic parameters $\mathrm{Km}$ and Vmax were calculated by Lineweaver-Burk equation chosen according to the properties of substrate concentration, the linear transformation of MichaelisMenten equation (Segel, 1975):

$\frac{1}{V}=\frac{K m}{V \max } \cdot \frac{1}{[S]}+\frac{1}{V \max }$

Where $\mathrm{V}$ is the enzyme reaction velocity (mg hydrolyzed urea- $\mathrm{N} \cdot \mathrm{kg}^{-1} \mathrm{dry}$ soil $\left.\cdot 5 h^{-1}\right),[S]$ is the concentration of substrate $\left(\mathrm{mmol} \mathrm{L}^{-1}\right), \mathrm{Km}$ is the Michaelis constant $\left(\mathrm{mmol} \mathrm{L}^{-1}\right)$, and $\mathrm{V}_{\max }$ is the maximum enzyme reaction velocity $(\mathrm{mg}$ hydrolyzed urea-N $\cdot \mathrm{kg}^{-1}$ dry soil $\cdot 5 \mathrm{~h}^{-1}$ ). $\mathrm{K}_{m}$ indicates the affinity of urease to its specific substrate urea, and gives the substrate concentration at which the reaction rate reaches half of its maximum value $\left(\mathrm{V}_{\max } / 2\right)$.

\section{Thermodynamic parameters}

The temperature dependence of the reaction rate constant $(\mathrm{k})$ of soil urease served as the basis for fitting to Arrhenius equation (Trasar-Cepeda et al., 2007).

$\mathrm{k}=A \mathrm{e}^{(-\mathrm{Ea} / \mathrm{RT})}$

Where $\mathrm{Ea}$ is the activation of energy $(\mathrm{kJ}$ $\left.\mathrm{mol}^{-1}\right), A$ is the pre-exponential factor, $\mathrm{R}$ is the gas constant $\left(8.314 \mathrm{~J} \cdot \mathrm{mol}^{-1} \cdot \mathrm{K}^{-1}\right)$, $\mathrm{T}$ is the absolute temperature in Kelvin 
$(\mathrm{K})$, and $\mathrm{k}$ is the calculated reaction rate constant. The temperature coefficient $\left(Q_{10}\right)$ was calculated by the equation:

$\mathrm{Q}_{10}=\mathrm{e}^{10 \mathrm{E} / \mathrm{RT}(\mathrm{T}+10)}$

The enthalpy of activation $(\Delta \mathrm{H})$ was calculated by the equation:

$\Delta \mathrm{H}=\mathrm{Ea}-\mathrm{RT}$

Where $\Delta \mathrm{H}$ is the enthalpy of activation $\left(\mathrm{kJ} \mathrm{mol}{ }^{-1}\right)$.

\section{Statistical analysis}

All data were calculated on the basis of oven-dried soil, and represented as means \pm standard deviation of $3 \times 3$ data. The effects of urease inhibitors, temperature, incubation time, and their interactions on kinetic and thermodynamic parameters of soil urease were analyzed by a two-way analysis of variance (ANOVA) with the General Linear Models (GLM) procedure of SPSS 11.5 for windows, and the differences among treatment means were performed by Duncan's multiple test at $p$ $<0.05$ (SPSS 2000).

\section{RESULTS AND DISCUSSION}

The two-way ANOVA results of kinetic and thermodynamic parameters showed that urease inhibitor, environmental temperature, incubation time, and their interactions mostly had significant effect on $\mathrm{K}_{m}, \mathrm{~V}_{\max }, \mathrm{V}_{\max } / \mathrm{K}_{m}, E a, \mathrm{Q}_{10}$ and $\Delta \mathrm{H}$ of soil urease (Table 1).

\section{Characteristics of Michaelis kinetic parameters}

The patterns of the reaction velocity (V) with substrate concentration ([S]) were evaluated (Figure 1). From this figure it is seen that the reaction velocity was lower in the presence of urease inhibitors when compared to the control (in the absence of inhibitors) at the same substrate concentration. With substrate concentration increasing, the reaction velocity increased, and then kept constant with a maximum value when substrate concentration increased to a certain value (Fig. 1a), which fulfilled the basic conditions of Michaelis-Menten equation.

The $\mathrm{K}_{m}$ values of soil urease in control treatment varied from 34.71 to $309.08 \mathrm{mmol} \mathrm{L}^{-1}$ (Figure 2) at three experimental temperatures, which was slightly higher than that observed in other studies (Ladd, 1985; Gianfreda et al., 1992), being due to the differences of soil physicochemical characteristics, e.g. organic C. Higher soil organic C (29.20 g $\mathrm{kg}^{-1}$ ) in the present soil could trap soil urease and slow down the diffusion of the substrate, which prevents soil urease from interacting with its substrate.

The $\mathrm{K}_{m}$ values of soil urease in the presence of inhibitors were significantly higher, compared with the control, which may be attributed to the formation of inhibitor-urease complex, thereby decreasing the affinity of urease to its specific substrate urea, or the conformational changes in enzyme protein making its active sites less accessibility to its substrate (Vieth and Venkatasubramanian, 1973; Juan et al., 2009).

The $\mathrm{K}_{m}$ values varied between the urease inhibitors. $\mathrm{K}_{m}$ values of test inhibitor treatments followed in the order of NBPT $>$ PPD $>\mathrm{HQ}$, indicating that their effectiveness on urease was in the order of NBPT $>$ PPD $>$ HQ, confirming the previous studies (Chai and Bremner, 1987; Bremner and Chai, 1989; Wang et al., 1991). HQ inhibition of urease was least known of all three inhibitors studied here. However, it is suspected that for this 
Table 1. Results of two-way ANOVA of kinetic and thermodynamic parameters of soil urease.

\begin{tabular}{|c|c|c|c|c|c|c|c|c|c|c|c|c|}
\hline \multirow{2}{*}{ Factor $^{a}$} & \multicolumn{2}{|c|}{$\mathbf{K m}$} & \multicolumn{2}{|c|}{$V \max$} & \multicolumn{2}{|c|}{$V \max / \mathbf{K m}$} & \multicolumn{2}{|c|}{$E a$} & \multicolumn{2}{|c|}{$\mathbf{Q}_{10}$} & \multicolumn{2}{|c|}{$\Delta \mathbf{H}$} \\
\hline & $F$ & $P^{\mathrm{b}}$ & $F$ & $P$ & $F$ & $P$ & $F$ & $P$ & $F$ & $P$ & $F$ & $P$ \\
\hline $\mathbf{A}$ & 1101.27 & $0.00^{* * *}$ & 1150.57 & $0.00^{* * *}$ & 12.53 & $0.00^{* * *}$ & $\mathrm{ND}^{\mathrm{c}}$ & ND & 1641.33 & $0.00^{* * *}$ & 4.81 & $0.02 *$ \\
\hline B & 23.71 & $0.00^{* * *}$ & 5.38 & $0.01 * * *$ & 42.21 & $0.00^{* * *}$ & 499.18 & $0.00^{* * *}$ & 1527.62 & $0.00^{* * *}$ & 1497.54 & $0.00^{* * *}$ \\
\hline C & 2.04 & 0.14 & 59.90 & $0.00^{* * *}$ & 24.86 & $0.00^{* * *}$ & 0.01 & 0.99 & 0.03 & 0.97 & 0.03 & 0.97 \\
\hline $\mathbf{A B}$ & 3.19 & $0.02 *$ & 10.69 & $0.00^{* * *}$ & 47.95 & $0.00^{* * *}$ & ND & ND & 3.92 & $0.01 * *$ & 0.00 & 1.00 \\
\hline AC & 1.28 & 0.29 & 20.29 & $0.00^{* * *}$ & 1516 & $0.00^{* * *}$ & ND & ND & 0.00 & 1.00 & 0.00 & 1.00 \\
\hline BC & 7.59 & $0.00^{* * *}$ & 6.88 & $0.00^{* * *}$ & 17.35 & $0.00^{* * *}$ & 1.32 & 0.30 & 4.03 & $0.01 * *$ & 3.96 & $0.01 * *$ \\
\hline $\mathbf{A B C}$ & 24.35 & $0.00^{* * *}$ & 3.48 & $0.00^{* * * *}$ & 73.04 & $0.00^{* * *}$ & ND & ND & 0.012 & 1.00 & 0.00 & 1.00 \\
\hline
\end{tabular}

${ }^{\mathrm{a}} \mathrm{A}, \mathrm{B}$ and $\mathrm{C}$ represent incubation temperature, urease inhibitor, and incubation time, respectively. ${ }^{\mathrm{b} *}$, ** and $* * *$ represent $\mathrm{p}<0.05,<0.01$ and $<0.001$, respectively. ${ }^{\mathrm{c}} \mathrm{ND}$ : no data.
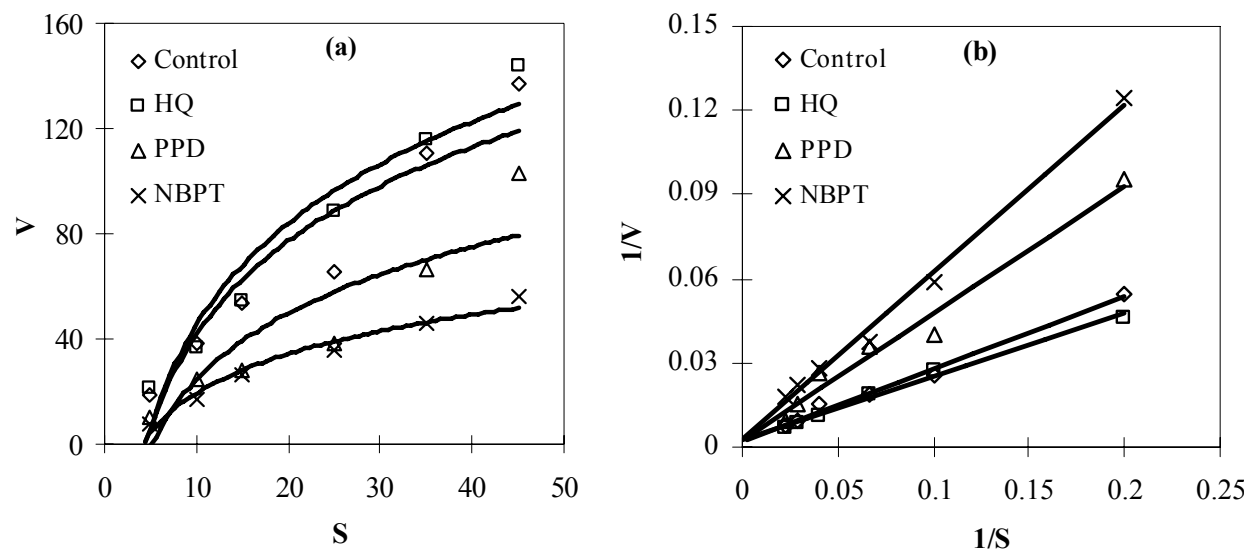

Figure 1. The effect of urease inhibitors on kinetic plots of soil urease. (a) the saturation curve $\mathrm{V} \propto \mathrm{S}$; (b): the linear transformation curve $1 / \mathrm{V} \propto 1 / \mathrm{S}$; V: the reaction velocity (mg hydrolyzed urea-N kg${ }^{-1}$ dry soil $\left.5 \mathrm{~h}^{-1}\right)$; $\mathrm{S}$ : substrate concentration $\left(\mathrm{mmol} \mathrm{L}^{-1}\right)$.

inhibition responsibility was trace amounts of quinone, behaving with a double mode of inhibitory action on urease, namely through the arylation of the enzyme thiol group and reactive oxygen species (ROS) generation, notably $\mathrm{H}_{2} \mathrm{O}_{2}$, resulting in the oxidation of the thiol group ( Krajewska and Zaborska, 2007; Zaborska et al., 2007). NBPT had higher effects on urease inhibition than PPD in soil, which could be due to the formation of a compound (NBPTO, N-(n- butyl) phosphoric triamide) that is much more effective that NBPT for inhibition of urease activity (Andrews et al., 1986; Chai et al., 1988; McCarty and Bremner, 1989; Christianson et al., 1990; Benini et al., 1996).

The $\mathrm{K}_{m}$ values increased significantly with an increase in incubation temperature (Statistical results were not shown), which was probably due to the reduction of amounts of effective active sites covered by humus accompanied with 


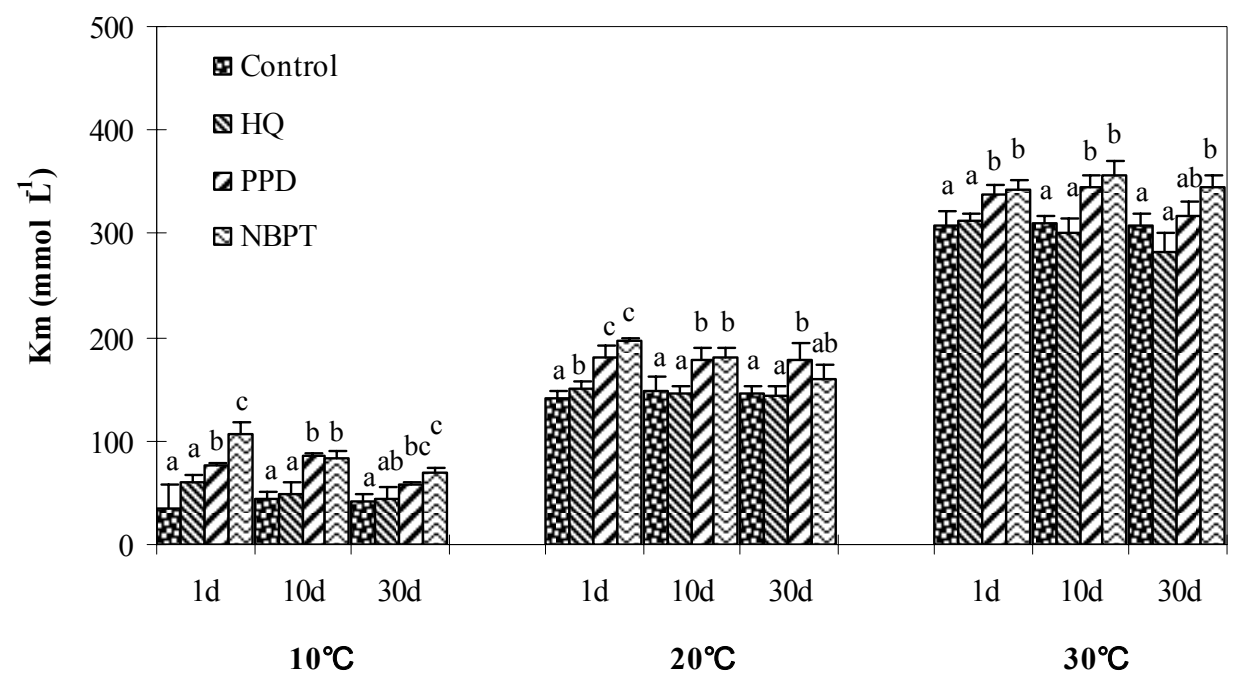

Figure 2. The effect of urease inhibitors on $K_{m}$ values of soil urease. Values sharing the same letter are not significantly different $(p<0.05)$ for the treatments according to the Duncan significant difference test.

temperature (Figure 2). The changes of $\mathrm{Km}$ with temperature indicated that urease inhibitors could cause greater inhibitory effect at relatively lower temperature, being probably due to the higher decomposition rate of inhibitor at higher temperature.

With incubation time, $\mathrm{K}_{m}$ significantly decreased (Statistical results were not shown). However, the time for Km values to reach the control level differed. In general, the duration of PPD and NBPT was longer than that of HQ (ca. 30 days vs. 10 days). It appears that initially PPD inhibited urease activity, and during this time at least part of the PPD was converted to diamidophosphate (DAP); then as the activity of PPD declined, DAP began to inhibit soil urease (Hendrickson and O'Connor, 1987; Krajewska and Zaborska, 2007).

Similarly, researches have shown that NBPT itself is not an active urease inhibitor, but instead, must be converted to its oxon analog N-(n-butyl) phosphoric triamide (NBPTO) which is more effective than NBPT (McCarty et al., 1989; Creason et al., 1990; Manunza et al., 1999). Therefore, during incubation period, the relative efficiency of phosphoroamides depended on the relative rate and time of formation of the converted analogs and their stability and/or absorption in soil.

The changes of $\mathrm{K}_{m}$ with incubation time also provided evidences that urease inhibitors PPD and NBPT were much better than HQ.

Figure 3 shows that the Vmax value of Control treatment varied from 255.33 to $1507.94 \mathrm{mg}$ hydrolyzed urea-N $\cdot \mathrm{kg}^{-1}$ dry soil $\cdot 5 \mathrm{~h}^{-1}$ at test temperatures. With application of urease inhibitors, Vmax decreased, being due to the formation of inhibitor-enzyme complex retarding the formation and dissociation of enzymesubstrate complex (Lai and Tabatabai, 1992). 


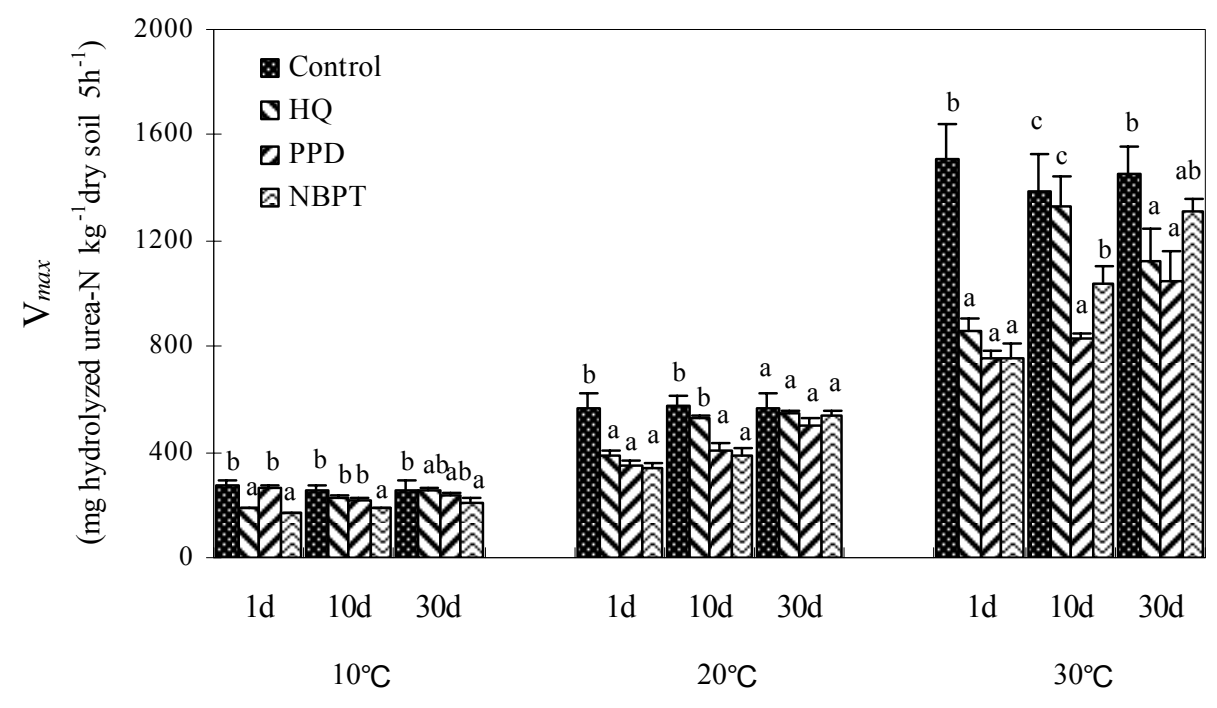

Figure 3. The effect of urease inhibitors on Vmax values of soil urease. Values sharing the same letter are not significantly different $(p<0.05)$ for the treatments according to the Duncan significant difference test.

The $\mathrm{V}_{\max }$ values varied between the inhibitors (Table1, Figure 3). In general, the Vmax values were lower in the presence of PPD and NBPT than HQ, indicating that PPD and NBPT had higher inhibitory effectiveness on soil urease. As a slow, tight-binding inhibitor, PPD exhibited slow rate of initial interaction with urease enzyme by slow isomerization of an enzyme-inhibitor complex, and caused a significant inhibition even when the molar concentration of inhibitor was not significantly greater than that of the enzyme (Morrison, 1982). As phosphoric triamide urease inhibitors, the oxygen analogs showed better urease inhibition than those of thio compounds. So the effectiveness of NBPT may be related to the time and rate of its oxygen analog (NBPTO), and the synergistic effect of two compounds (NBPT, NBPTO) in soil (Christianson et al., 1990).
The results showed that Vmax increased with an increase in temperatures (Figure 3). Carmona et al. (1990) showed that higher concentration of NBPT was necessary at higher temperature to retard urease activity, similarly demonstrating that the enzymatic reaction rate increased with temperature. $\mathrm{V}_{\max }$ of soil urease for all three inhibitors during their incubation with the enzyme increased at all temperatures studied, but the ascending trend differed with the inhibitor type. The decrease in $\mathrm{V}_{\max }$ with increasing temperature may be attributed to the decrease of effectiveness in their inhibiting action on enzymes for test urease inhibitors by molecule decomposition.

The ratio between $\mathrm{Vmax}$ and $\mathrm{Km}$ $\left(\mathrm{V}_{\max } / \mathrm{K}_{m}\right)$ has been considered as an index of the catalytic capacity of enzyme through enzymatic reactions. Compared with control, $\mathrm{V}_{\max } / \mathrm{K}_{m}$ decreased with 
application of test inhibitors significantly (data not shown), indicating that the inhibitors could decrease the catalytic capacity of soil urease. However, there was no consistent trend for $\mathrm{V}_{\max } / \mathrm{K}_{m}$ influenced by inhibitor type, incubation temperature and incubation time.

It was shown from the above variations of $\mathrm{Km}$ and $\mathrm{Vmax}$ that the mechanism of HQ, PPD and NBPT on soil urease was all of mixed inhibition, beings not in accordance with the previous studies of PPD in a pure enzyme system (McCarty et al., 1990; Krajewska and Zaborska, 2007).

\section{Characteristics of thermodynamic parameters}

The activation energy (Ea), enthalpy of activation $(\Delta \mathrm{H})$ and temperature coefficients $\left(\mathrm{Q}_{10}\right)$ of urease inhibition ranged from $21.06-23.99 \mathrm{~kJ} \cdot \mathrm{mol}^{-1}$, $19.08-21.64 \mathrm{~kJ} \cdot \mathrm{mol}^{-1}$ and $1.32-1.42$, respectively (Table 2). The Ea values obtained are within the ranges reported by Kumar and Wagenet (1984) and by Dalal (1975), but lower than those reported by other authors (Lai and Tabatabai, 1992;
Trasar-Cepada et al., 2007), which is probably due to the differences in the tested soil.

The stronger the protection of urease brought by the association with soil organic- or inorganic-mineral complexes (Nannipieri et al., 1991), the higher the energy barrier overcame during the formation of enzyme-substrate complex. Changes of Ea may reflect the stabilization of the urease enzyme by soil components.

Up to now, only limited information has been available regarding the $\mathrm{Q}_{10}$ of enzymes. The $\mathrm{Q}_{10}$ values $(1.32$ - 1.42) obtained in the present study were within the range reported in the literatures, ranging between 1.10 and 1.80 (Browman and Tabatabai, 1978; Frankenberger and Tabatabai, 1991).

Enzyme-catalyzed reactions are less sensitive to temperature changes than their chemical reactions. Thus, although the uncatalyzed reaction rate may double for every increase of $10^{\circ} \mathrm{C}$, the enzymecatalyzed reactions rate generally increased by a factor of less than two (Tabatabai, 1994).

Table 2. Thermodynamic parameters of soil urease.

\begin{tabular}{|c|c|c|c|c|c|c|c|c|c|}
\hline \multirow{2}{*}{ Treatment } & \multicolumn{3}{|c|}{ Ea $\left(\mathrm{kJ} \mathrm{mol}^{-1}\right)$} & \multicolumn{3}{|c|}{$\Delta \mathrm{H}\left(\mathrm{kJ} \cdot \mathrm{mol}^{-1}\right)$} & \multicolumn{3}{|c|}{$\mathbf{Q}_{10}$} \\
\hline & Temperature range $\left({ }^{\circ} \mathrm{C}\right)$ & $\mathbf{E a}$ & $\mathbf{r}^{\mathrm{a}}$ & $10^{0} \mathrm{C}$ & $20^{0} \mathrm{C}$ & $30^{0} \mathrm{C}$ & $10^{0} \mathrm{C}$ & $20^{\circ} \mathrm{C}$ & $30^{\circ} \mathrm{C}$ \\
\hline Control & $10-30$ & 22.66 & $0.997 * * *$ & 20.31 & 20.22 & 20.14 & 1.39 & 1.36 & 1.33 \\
\hline HQ & $10-30$ & 21.06 & $0.977 * *$ & 19.25 & 19.16 & 19.08 & 1.37 & 1.34 & 1.32 \\
\hline PPD & $10-30$ & 22.73 & $0.969 * *$ & 20.37 & 20.29 & 20.21 & 1.40 & 1.37 & 1.34 \\
\hline NBPT & $10-30$ & 23.99 & $0.986 * *$ & 21.64 & 21.55 & 21.47 & 1.42 & 1.38 & 1.36 \\
\hline
\end{tabular}

a** and ${ }^{* * *}$ represent $\mathrm{p}<0.01$ and $<0.001$, respectively.

The higher the value of $\mathrm{Q}_{10}$, the closer the behaviour of the reaction resembles that of a reaction not catalyzed by enzymes.

HQ caused the thermodynamic parameters of soil urease keep constant or slightly decrease, while PPD and NBPT caused the parameters slightly increase, possibly due to their different effectiveness and acting time, i.e., HQ had a weaker effectiveness and a shorter acting time, which made the urease's energy hindrance keep constant or slightly decrease; PPD and NBPT increased the energy hindrance of enzymatic catalytic 
reaction by holding active sites of urease, and further, increased the activation energy Ea. With increasing temperature, the thermodynamic parameters $\mathrm{Q}_{10}$ and $\Delta \mathrm{H}$ slightly decreased but not significantly. For urease, the values of Ea, $\Delta \mathrm{H}$ and $\mathrm{Q}_{10}$ differed among the three inhibitors and temperatures treatments, although the differences were generally small.

In this study, despite the fact that only one soil sample was used, the results obtained are of sufficient significance to make reliable conclusions of general interest that are presumably extendable to other soils and agricultural management practices. Comparing with the variation of kinetic and thermodynamic parameters as affected by the inhibitors, we concluded that inhibitory effects of urease inhibitors on soil urease are more dependent on their influencing on kinetic behaviors rather than on thermodynamic ones.

\section{ACKNOWLEDGEMENTS}

Financial supports from National Basic Research Program of China (973 Program) (2007CB109307), Study and Extension on Benefit Fertilization Application Technique (2008BADA4B06) and Chinese Government Science and Technology Supporting Program (2006BAD10B01) are gratefully acknowledged. We thank Professor L. K. Zhou for his critical review of our manuscript, and the staffs in Department of Applied Soil Biochemistry, Institute of Applied Ecology, Chinese Academy of Sciences for their academic and technical assistance.

\section{REFERENCES}

Andrews, R. K., Dexter, A., Blakeley, R. L., Zerner, B. 1986. Jack bean urease (EC3.5.1.5.).8. on the inhibition of urease by amides and ester of phosphoric acid. J. Am. Chem. Soc. 108, 7124-7125.
Bandick, A. K., Dick, R. P. 1999. Field management effects on soil enzyme activities. Soil Biol. Biochem. 31, 1471-1479.

Benini, S., Gessa, C., Ciuril, S. 1996. Bacillus pasteurii urease: A heteropolymeric enzyme with a binuclear nickel active site. Soil Biol. Biochem. 28(6), 819-821.

Beyrouty, C. A., Sommers, L. E., Nelson, D. W. 1988. Ammonia volatilization from surface applied urea as affected by several phosphoroamide compounds. Soil Sci. Soc. Am. J. 52, 1173- 1178 .

Blennerhassett, J. D., Quin, B. F., Zaman, M., Ramakrishnan, C. 2006. The potential for increasing nitrogen response using Agrotain treated urea. Proceed NZ Grassland Assoc 68, 297-301.

Bremner, J. M., Chai, H. S. 1989. Effects of phosphoroamides on ammonia volatilization and nitrite accumulation in soil treated with urea. Biol. Fertil. Soils 8, 227-230.

Browman, M. G.., Tabatabai, M. A. 1978. Phosphodiesterase activity of soils. Soil Sci Sco Am J. 72, 284-290.

Byrnes, B. H., Freney, J. R. 1995. Recent development on the use of urease inhibitors in the tropics. Fertilizer Research 42(1/3), 251-259.

Cai, G. X., Freney, J. R., Muirhead, W. A., Simpson, J. R., Chen, D. L., Trevitt, A. C. F. 1989. The evaluation of urease inhibitor to improve the efficiency of urea as a N-source for flooded rice. Soil Biol. Biochem. 21(1), 137-145.

Carmona, G., Christianson, C. B., Byrnes, B. H. 1990. Temperature and low concentration effects of the urease inhibitor $\mathrm{N}$-(n-butyl) thiophosphoric triamide (NBPT) on ammonia volatilization from urea. Soil Biol. Biochem. 2, 933-937.

Chai, H. S., Bremner, J. M. 1987. Evaluation of some phosphoroamides as soil urease inhibitors. Biol. Fertil. Soils 3, 189-194.

Chai, H. S., Bremner, J. M., McCarty, G. W. 1988. Effect of $\mathrm{N}$-(n-butyl) thiophosphoric triamide on hydrolysis of urea by plant, microbial, and soil urease. Agron. Abstr. p213.

Christianson, C. B., Byrnes, B. H., Carmona G. 1990. A comparison of the sulfur and oxygen of phosphoric triamide urease inhibitors in 
reducing urea hydrolysis and ammonia volatilization. Fertilizer Research 26, 21-27.

Creason, G. L., Schmidt, M. R., Douglass, E. A., Hendrickson, L. L. 1990. Urease inhibitory activity associated with N-(n-butyl) thiophosphoric triamide is due to formation of its oxon analog. Soil Biol. Biochem. 22, 209-211.

Dalal, R. C. 1975. Effect of toluene on the energy barriers in urease activity of soils. Soil Sci. 120, 256-260.

Frankenberger, Jr. W. T., Tabatabai, M. A. 1991. L-Asparaginase activity of soils. Biol. Fertil. Soils 11, 6-12.

Gianfreda, L., Rao, M. A., Violante, A. 1992. Adsorption, activity and kinetic properties of urease on montmorillonite, aluminum hydroxide and $\mathrm{Al}(\mathrm{OH}) \mathrm{X}-$ montmorillonite complexes. Soil Biol. Biochem. 24, 51-58.

Gioacchini, P., Nastri, A., Marzadori, C., Giovannini, C., Antisari, L. V., Gessa, C. 2002. Influence of urease and nitrification inhibitors on $\mathrm{N}$ losses from soils fertilized with urea. Biol. Fertil. Soils 36, 129-135.

Hendrickson, L. L., O'Connor, M. J. 1987. Urease inhibition by decomposition products of phenylphosphorodiamidate. Soil Biol. Biochem. 19(5), 595-597.

Juan, Y. H., Chen, L. J., Wu, Z. J., Wang, R. 2009. Kinetics of soil urease affected by urease inhibitors at contrasting moisture regimes. J. Soil Sci. Plant Nutr. 9(2), 125 - 133.

Keerthisinghe, D. G.., Freney, J. R. 1994. Inhibition of urease activity in flooded soils: Effect of thiophosphorictriamides and phosphorictriamides. Soil Biol. Biochem. 26, 1527-1533.

Krajewska, B., Zaborska, W. 2007. Jack bean urease: The effect of active-site binding inhibitors on the reactivity of enzyme thiol groups. Bioorganic Chemistry 35(5), 355-365.

Kumar, V., Wagenet, R. J. 1984. Urease and kinetics of urea transformation in soils. Soil Sci 137, 263-269.

Ladd J. N. 1985. Soil enzymes. In: Vaughan D., Malcolm R. E., (eds.). Soil organic matter and biological activity. pp, 176-221.

Lai, C. M., Tabatabai, M. A. 1992. Kinetic parameters of immobilized urease. Soil Biol. Biochem. 24(3), 225-228.
Lu, R. K. (ed). 2000. Methods of soil and agrochemistry analysis. Chinese Agricultural Science and Technology Press, Beijing. (in Chinese).

Luo, Q. X., Freney, J. R., Keerthisighe, D. G.., Peoples, M. B. 1994. Inhibition of urease activity in flooded soils by phenylphosphorodiamide and $\mathrm{N}$-(n-butyl) thiophosphorictriamide. Soil Biol. Biochem. 26(8), 1059-1065

Makboul, H. E., Ottow, J. C. G. 1979. Clay minerals and the Michaelis constant of urease. Soil Biol. Biochem. 11(6), 683-686.

Manunza, B., Deiana, S., Pintore, M., Gessa, C. 1999. The binding mechanism of urea, hydroxamic acid and N-(n-butyl)-phosphoric triamide to the urease active site. A comparative molecular dynamic study. Soil Biol. Biochem. 31, 789-796.

McCarty, G. W., Bremner, J. M., Chai, H. S. 1989. Effect of N-(n-butyl) thiophosphoric triamide on hydrolysis of urea by plant, microbial and soil ureases. Biol. Fertil. Soils 8, 123-127.

McCarty, G. W., Bremner, J. M., Lee J. S. 1990. Inhibition of plant and microbial urease by phosphoroamides. Plant Soil 127, 269-283.

Morrison, J. F. 1982. The slow-binding and slow, tight-binding inhibition of enzymecatalyzed reactions. Trends. Biochem. Sci. 7, 102-105.

Nannipieri, P., Ceccanti, B., Cervelli, S., Conti, C. 1982. Hydrolases extracted from soil: Kinetic parameters of several enzymes catalysing the same reaction. Soil Biol. Biochem. 5, 429-432.

Nannipieri, P., Ceccanti, B., Cervelli, S., Sequi, P. 1978. Stability and kinetic properties of humus-urease complexes. Soil Biol. Biochem. $10,143-147$

Nannipieri, P., Ciardi, C., Palazzi, T., Badalucco, L. 1990. Short-term nitrogen reactions following the addition of urea to a grass-legume association. Soil Biol. Biochem. 22(4), 549-553.

Nannipieri, P., Gelsomino, A., Felici, M. 1991. Method to determine guaiacol oxidase activity in soil. Soil Sci. Soc. Am. J. 55, 1347-1352.

Pedrazzini, F., Tarsitano, R., Nannipieri, P. 1987. The effect of phenyl phosphorodiamidate on urease activity and ammonia volatilization in flooded rice. Biol. Fertil. Soils 3, 183-188 . 
Segel, I. H. 1975. Enzyme Kinetics. Wiley, New York.

Singh, J., Saggar, S., Bolan, N. S., Zaman, M. 2008. The role of inhibitors in the bioavailability and mitigation of nitrogen losses in grassland ecosystems. In: Chemical Bioavailability in Terrestrial Environment. (Eds. Naidu et al) Elsevier, Amsterdam, The Netherlands. ISBN 978-0-444-52169-9. pp329-362.

SPSS. 2000. SPSS 10.0 for windows. SPSS, Chicago, IL.

Tabatabai, M. A. 1994. Soil enzymes. In Weaver, R. W., Angle, J. R., Bottomley, P. S (eds) Methods of soil analysis. Part 2: microbiological and biochemical properties. Soil Science Society of America, Madison, WI, pp 775-833.

Trasar - Cepeda, C., Gil - Sotres, F., Leiros, M. C. 2007. Thermodynamic parameters of enzymes in grassland soils from Galicia NW Spain. Soil Biol. Biochem. 30, 311-319.

Varel, V. H. 1997. Use of urease inhibitors to control nitrogen loss from livestock waste. Bioresource Technology 62, 11-17.

Vieth, W. A., Venkatasubramanian, K. 1973. Enzyme engineering, PartIII. Properties of immobilized enzyme systems. Chemistry Technology 3, 18-29.
Wang, Z. P., Van Cleemput, O., Demeyer, P. 1991. Effect of urease inhibitors on urease hydrolysis and ammonia volatilization. Biol. Fertil. Soils 11, 43-47.

Yeomans, J. C., Bremner, J. M. 1986. Effects of urease inhibitors on denitrification. Commun Soil Sci. Plant Analy. 17, 63-73.

Zaborska, W., Krajewska, B., Kot, M., Karcz, W. 2007. Quinone-induced inhibition of urease: Elucidation of its mechanisms by probing thiol groups of the enzyme. Bioorganic Chemistry 35, 233-242.

Zhu, Z. L., Chen, D, L. 2002. Nitrogen fertilizer use in China-Contributions to food production, impact on environment and best management strategies. Nutri Cycl Agroecosys 63, 117-127.

Zornoza, R., Guerrero, C., Mataix-Solera, J. M., Arcenegui, V., Garcia-Orenes, F., MataixBeneyto, J. 2006. Assessing air-drying and rewetting pre-treatment effect on some soil senzyme activities under Mediterranean conditions. Soil Biol. Biochem. 38, 2125-2135. 